\title{
INTERGENERATIONAL INCEST AVERSION
}

This is a pre-print of an accepted manuscript of an article published by Elsevier in Evolution \& Human Behavior. Please reference the final publication. The final proofed version might differ from the current document.

Intergenerational Incest Aversion: Self-reported Sexual Arousal and Disgust to Hypothetical Sexual Contact with Family Members

\author{
Paula Kresanov $^{1}$, Jennifer Kotler ${ }^{2}$, Michael Seto ${ }^{3}$, Debra Lieberman ${ }^{4}$, Pekka Santtila ${ }^{1,5}, \&$ \\ Jan Antfolk ${ }^{1}$ \\ ${ }^{1}$ Department of Psychology, Åbo Akademi University, Turku, Finland \\ ${ }^{2}$ Harvard University, Department of Organismic \& Evolutionary Biology, Cambridge, MA, US \\ ${ }^{3}$ Royal Ottawa Health Care Group, Ottawa, Ontario, Canada \\ ${ }^{4}$ Department of Psychology, University of Miami, Coral Gables, FL, US \\ ${ }^{5}$ Faculty of Arts and Sciences, New York University, Shanghai, China
}

Author Note

The first author was funded by a personal grant from the Jenny and Antti Wihuri foundation. The last author was funded by a grant from the Academy of Finland (Grant no. 298513).

Corresponding Author:

Paula Kresanov

Psychology, Åbo Akademi

Tehtaankatu 2 20500, Turku, Finland

e-mail: paula.kresanov@abo.fi 


\title{
INTERGENERATIONAL INCEST AVERSION
}

\begin{abstract}
The biological costs of inbreeding are expected to have shaped human incest aversion. These costs depend on biological sex, relatedness, and age. Whereas previous studies have focused on investigating how these factors modulate incest aversion in siblings and cousins - family members of the same generation-here we examined relatives of different generations. In a population-based sample, 2,499 respondents reported reactions to imagined sexual behaviors with either a biological child or parent, a niece/nephew or aunt/uncle, or a stepchild or stepparent; these responses were compared to reactions to imagined sexual behaviors involving a friend's child or parent. Replicating prior results, women report stronger incest aversions than do men. We extend previous findings by showing that incest aversions tended to be stronger between close (vs. more distant) intergenerational relatives. Indeed, for biological relatives, decreased degree of relatedness was associated with decreased incest aversion, and for biological relatives, the certainty in relatedness was also positively associated with incest aversion. As expected, age modulated sexual aversion for unrelated, but not related, target individuals. Sexual aversions toward steprelatives did not differ from sexual aversions to biological relatives.

Keywords: Incest Aversion, Inbreeding, Sexual Arousal, Disgust, Sexual Abuse
\end{abstract}


INTERGENERATIONAL INCEST AVERSION

1. Intergenerational Incest Aversion: Self-reported Sexual Arousal and Disgust to Hypothetical Sexual Contact with Family Members

Social norms and laws proscribe sexual relationships between closely related family members, such as first- second-, and, in some cases, third-degree relatives (Thornhill, 1991). One likely reason for this is the detrimental biological effects of inbreeding (i.e., the production of offspring from closely related individuals; Westermarck, 1891). Inbreeding is, in most cases, evolutionarily harmful (Darwin, 1876; Frankham, 1995; Spielman, Brook, Briscoe, \& Frankham, 2004). For most of our genes, one allele has been inherited from our mother and the other from our father. When these two alleles differ (i.e., heterozygosity), one allele can offer protection from a deleterious mutation present in the other allele. However, if the two alleles are identical (i.e., homozygosity), these mutations are more likely to manifest, and, in turn decrease survival (e.g., Bressan \& Kramer, 2015). Inbreeding increases the risks of inheriting similar deleterious mutations, decreasing the fitness of resulting offspring, and, by extension, parents and other close relatives (Bittles \& Neel, 1994; Charlesworth, Charlesworth, Willis, \& Willis, 2009; Tooby, 1982).

Throughout human history, strong selective pressure against inbreeding is expected to have led to several psychological adaptations that effectively regulate our mate choice to exclude the closest family members (Lieberman \& Antfolk, 2015). As a result, both humans (Thornhill, 1991; Wolf, 1968; Wolf, 1966) and many non-human animals (Bretman, Wedell, \& Tregenza, 2004; Szulkin, Zelazowski, Nicholson, \& Sheldon, 2009) display a general lack of sexual attraction towards close genetic kin, that is, incest aversion. However, the costs of inbreeding depend 
on several factors, and psychological adaptations regulating mate choice are expected to reflect this.

\subsection{Sex, Relatedness, and the Costs of Inbreeding}

Parental investment theory (Trivers, 1972) postulates that the fitness costs of inbreeding are greater for females than males. Because human reproduction requires more obligatory investment from females than males, females have lower maximum lifetime fecundity. This means that an instance of sub-optimal breeding, such as inbreeding, has a more negative impact on overall reproductive success of females compared to males. In line with this, several studies have shown that women display stronger aversions to incest as compared to men (e.g., Antfolk, Karlsson, Bäckström, \& Santtila, 2012; Bjorklund \& Kipp, 1996; Fessler \& Navarrete, 2004; Lieberman \& Lobel, 2012; Marcinkowska, Moore, \& Rantala, 2013).

The fitness consequences of inbreeding also depend on the actual degree of relatedness between the mating individuals. This is because the increase in genetic homogeneity is a function of relatedness, such that the more closely related the parents, the higher the genetic homogeneity in the offspring (Bittles \& Neel, 1994). Indeed, a central finding from previous studies is that the strength of human incest aversion depends on relatedness: The higher the degree of biological relatedness between two individuals, the stronger the incest aversion. For example, Antfolk and colleagues (2012) showed that descriptions of sex with a sibling elicited more negative reactions than descriptions of sex with a half sibling, which, in turn, elicited more negative reactions than descriptions of sex with a first cousin (see also Lespiau \& Kaminski, 2016). Evidence of how the degree of relatedness affects intergenerational incest aversion (i.e., sexual aversion between parents and children, or between aunts/uncles and nieces/nephews) is, to our best knowledge, scarce.

\subsection{Kinship Cues and Subjective Certainty in Relatedness}


Due to the nature of childbirth, human females can be sure of their own biological relatedness to their children. In all other situations, biological relatedness is uncertain and relies on the availability of cues indicating biological relatedness. Hence, rather than following the exact degree of relatedness, incest aversion is expected to depend largely on perceived relatedness. Prior work on kin detection in humans suggests that perceived relatedness is based on the presence or absence of kinship cues (e.g., co-residence) that can be assumed to have ancestrally correlated with genetic relatedness (Wolf \& Durham, 2004). Studies also suggest that the strength of incest aversion reflect this (Antfolk, Lindqvist, Albrecht, \& Santtilla, 2014; Lieberman, Tooby, \& Cosmides, 2003). Lieberman and her research group found that, with respect to siblings, kin detection is conveyed by two distinct cues: Co-residence in childhood (i.e., "the Westermarck effect"; Westermarck, 1891) and seeing a newborn in close association with a shared mother (e.g., being cared for and breast-fed by the mother; Lieberman, Tooby, \& Cosmides, 2007). Previous studies on the effect of perceived relatedness — or the effect of suggested kinship cues that influence these perceptions - on incest aversion have mainly focused on sibling relationships (Bevc \& Silverman, 1993; De Smet, Van Spreybroeck, \& Verplaetse, 2014; Fessler \& Navarrete, 2004; Royzman, Leeman, \& Sabini, 2008; Tidefors, Arvidsson, Ingevaldson, \& Larsson, 2010). By contrast, studies on the effects of perceived relatedness on intergenerational incest aversion are scarce. Three studies have addressed the question of how kinship cues affect incest aversion in fathers. Parker and Parker (1986) and Williams and Finkelhor (1995) concluded that decreased levels of caretaking were a risk factor for incest. According to Tal and Lieberman (2007), however, the same cues that regulate parents' positive investment in children also regulate incest aversion. This suggests that the relationship between decreased positive investment and incest is spurious. A father who is uncertain of his biological relationship with a child is less 
willing to direct positive investment towards this child (e.g., Anderson, Kaplan, \& Lancaster, 2007; Apicella \& Marlowe, 2004), but this uncertainty is also expected to decrease incest aversion to the same child. Indeed, the third study by Billingsley and colleagues (2018) found that perceptions of partner fidelity predicted incest aversion in fathers. Moreover, fathers' willingness to invest in children is associated with perceived relatedness to the child (Antfolk, Karlsson, Söderlund, \& Szala, 2017). Still, although theory suggests that perceived relatedness is also associated with incest aversion in intergenerational relationships, empirical evidence of this is limited for relationships outside the father-daughter relationship.

\subsection{Age and Sexual Interest}

Concerning unrelated individuals, sexual interest is strongly associated with age. Because early adolescence marks the beginning of sexual maturity (e.g., Mcdowell, Brody, \& Hughes, 2007), few adults are sexually interested in pre-adolescent individuals (Santtila et al., 2015; Seto, 2008). In terms of peak age interest, human males and females differ. Whereas most females are sexually interested in partners who are equal in age or slightly older than themselves, males, irrespective of their own age, tend to be interested in young sexually-mature females (Antfolk et al., 2015; Bergen, Antfolk, Jern, Alanko, \& Santtila, 2013; Hayes, 1995; Kenrick \& Keefe, 1992). In addition, as fertility decreases with older age (and more so for females than males), elderly individuals are also found less sexually interesting (Tripodi et al., 2015). The evolutionary explanation for these patterns is that sexual interest in individuals who are not fertile is selected against, because such an interest decreases one's chances of producing offspring (Kenrick \& Keefe, 1992).

Concerning closely related individuals, much less is known. To our knowledge, no previous study has thoroughly investigated the role of age and fertility in this context. However, there 
is some evidence that variations in fertility across the menstrual cycle are related to incest aversion, such that fertile women experience relatively stronger incest aversion (Antfolk, Lieberman, Albrecht, \& Santtila, 2014; Lieberman, Pillsworth, \& Haselton, 2011), but the potential effects of age-related variation in fertility have not been studied. Sexual interest generally increases as sexual targets become mature (to a certain age, after which the fertility of sexual targets declines). We do not expect to see this pattern if the target individual is a close relative. This is because the costs of incest are higher when the likelihood of conception is higher (i.e., during sexual maturity).

\subsection{Sexual Motivation and the Role of Disgust}

Current models of sexual behavior, such as the dual control model of sexual response (Bancroft \& Janssen, 2000), indicate that sexual interest is the result of both facilitators and repressors. More specifically, the model suggests that there are separate neural facilitator and repressor systems (Kurpisz, Mak, Lew-Starowicz, Nowosielski, \& Samochowiec, 2015). In the case of incest, a particularly important repressor is disgust. Prior research shows that disgust down-regulates sexual arousal (De Jong, Van Overveld, \& Borg, 2013; Koukounas \& McCabe, 2001; Rempel \& Baumgartner, 2003; Stark et al., 2005) and, conversely, that sexual arousal has an inhibitory effect on disgust (Stevenson, Case, \& Oaten, 2011). The response to a particular stimulus is shaped by the individual's receptivity to disgust and sexual arousal (De Jong et al., 2013). For example, a father with high paternity certainty could experience the thought of sex with his daughter as disgusting, whereas another father who has low paternity certainty might experience less disgust or even find it arousing. In accordance with this, sexual arousal should decrease, and disgust should increase, when the perceived costs of incest are perceived to be 
high-higher for females than males, for close versus distant relatives, and when certainty in relatedness is high versus low.

\subsection{The Current Study}

In the present study, our aim was to investigate intergenerational incest aversion both between biologically related family members (parents and children and between aunts/uncles and nieces/nephews) and between socio-legally related family members (non-biological parents and non-biological children). We also included unrelated adults and children (a friend's parent and a friend's child) as controls. To do this, we used the Finn-Kin data set (Albrecht et al., 2014). This data set was produced through two separate web-based data collections. In the first, respondents were asked questions concerning their own children, nieces, nephews, and then a friend's child (i.e., younger generation targets). In the second data collection, respondents were asked questions concerning their own parents, aunts, uncles, and a friend's parent (i.e., older generation targets). Importantly, in both data collections, respondents answered questions regarding actual individuals belonging to the aforementioned categories. Incest aversion was measured using reactions to prompts asking respondents to imagine sexual behaviors with these individuals. Two outcome measures were assessed: sexual arousal (i.e., a reverse measure of incest aversion) and disgust (i.e., a positive measure of incest aversion).

Based on the aforementioned theory and earlier findings, we expected that:

i) Women would display stronger incest aversion than men;

ii) Stronger incest aversion would be displayed to more closely related individuals than to less closely related individuals;

iii) For related individuals, certainty in the biological relatedness would be positively associated with incest aversion; 
iv) The age of unrelated target individuals would be associated with arousal and disgust: More sexual arousal and less disgust would be reported for fertile (vs. young and senescent) unrelated targets. However, we did not expect an increase in sexual arousal or a decrease in disgust for fertile (vs. young and senescent) related targets.

\section{Method}

\subsection{Respondents}

The sample included 2,499 heterosexual or mainly heterosexual adult respondents (74 homosexual or mainly homosexual respondents were excluded). Of these, 1,413 respondents assessed different hypothetical sexual acts with actual individuals from an older generation (i.e., their biological parents, stepparents, aunts/uncles, and/or parents of a friend), whereas 1,086 respondents assessed hypothetical sexual acts with individuals from a younger generation (i.e., their biological children, stepchildren, nieces/nephews, and/or child of a friend). Of the respondents, 826 were men and 1673 were women. The mean age was $34.0(S D=9.0)$ and ranged from 18 to 57 years of age. Age data from two individuals were missing. The sample was a randomized population-based sample of adults from the Central Registry in Finland. This registry includes the addresses of all individuals currently living in Finland. An invitation letter was sent to all of the sampled addresses. The invitation letter included a description of the entire study and a web-address for the online survey. As compensation for participation, the possibility of partaking in a lottery of gift cards was offered to participants. More details regarding the Finn-Kin study can be found in Albrecht et al. (2014). No other filtering of the available data was done than the one reported here.

\subsection{Ethical Permission}


The Finn-Kin study obtained approval from the Ethical Review Board at the Department of Psychology and Logopedics at Åbo Akademi University before data collection commenced.

\subsection{Measures}

2.3.1. Incest aversion. Incest aversion was measured by self-reported sexual arousal and disgust. Respondents reported reactions to imagined hypothetical sexual behavior with one actual individual belonging to the included target categories (i.e., family members and non-family members presented in the sexual scenarios). Both sexual arousal and disgust responses were given to unique verbal prompts: 1) "Imagine making out with [name]", 2) "Imagine [name] suggestively touching your thigh while in the sauna", and 3) "Imagine having sex with [name]". For both the sexual arousal and the disgust measures, responses were given on scale from 0 (not at all) to 100 (very), using a visual slider. The three measures of sexual arousal were aggregated into one score. The Cronbach's alpha was appropriate $(\alpha=.94)$. The three measures of disgust were also aggregated into one score. The Cronbach's alpha was appropriate $(\alpha=.93)$.

2.3.2. Certainty in relatedness. Certainty in relatedness to one's biological family members was assessed by asking respondents to answer the question: "How sure are you that [name] is related to you?" using scale from 0 (not at all) to 100 (completely certain). Women were not asked this question with respect to their biological child.

2.3.3. Target age. For each target, we also obtained age information. After replacing six unlikely high age values (99-9999) with the value 95 (assumed to be the highest likely value after a check of other data, e.g., the respondent's own age), the reported ages ranged from 0-95 with a mean age of $40.98(S D=24.59)$. We also created a categorical age variable with three levels: young (14 and under), fertile (15-50), and senescent (50 and above). Target individuals of 
the younger generation included both young targets and fertile targets, and targets of the older generation included both fertile and senescent targets.

2.3.5. Proportion of Co-residence Duration. For the older generation, we measured coresidence between the target child and the adult. For each year between the child's birth and 18 years of age, respondents were asked to report whether they had not lived (0), partly lived (0.5), or lived in the same household as the child (1). Responses were summed. To also consider the child's current age, we then calculated the proportion of the child's life (in years) until 18 years of age that the respondent and the child had lived together. This was done only for biological and step children. We removed 38 (1.36\%) observations where co-residence was reported to be longer than the child's age.

2.3.4. Sexual orientation. To measure sexual orientation, we considered responses to two items of the Schluter Russian Sexual Orientation Assessment (Schluter, 2002) measuring sexual behavior and/or sexual attraction: "If there exists, say, a spectrum of hetero/homosexuality (that is from "straight" to "gay"), where would you be located?" Response options ranged from 1 (completely heterosexual) to 5 (completely homosexual). If response to either of these two items was 3 or above, respondents $(n=74)$ were not included in the current study.

\subsection{Procedure}

All respondents partook in the Finn-Kin survey on sexuality and kinship (Albrecht et al., 2014). At an early stage of the survey, respondents reported the numbers of family members and non-family members of the target categories of interest. If a respondent reported having more than one family member or non-family member of a target category (e.g., three brothers), one of these were randomly selected for further questioning. Before subsequent questioning, the names of actual family members and non-family members of interest were obtained. When reporting the 
names, respondents were instructed to choose a name or nickname that made it easy for them to recall said family member. These names were later used in the prompts. Hence, a respondent could be presented with the prompt "Imagine having sex with [Joe]", having previously identified "Joe" to be their step-father. The names were not saved in the data file to avoid compromising respondent anonymity. By including names rather than nouns indicative of a certain type of relationship (e.g., biological child, niece from mother's side), we could eliminate the possibility that the nouns themselves confounded the results. Additionally, the use of names was believed to help respondents imagine the situation.

\subsection{Statistical Analyses}

All statistical analyses were conducted using $R$ ( $R$ Development Core Team, 2008). Descriptive data were obtained using the psych-package (Revelle, 2016). Because each respondent provided several responses (depending on the actual number of family members and non-family members of interest) for both sexual arousal and disgust, we analyzed data using a multi-level linear regression model with subject as a random intercept. This was done using the lme4package (Bates, Maechler, Bolker, \& Walker, 2015). To obtain ANOVA-type tables and pairwise comparisons between levels, we used the lsmeans-package (Lenth, 2016). Because separate analyses were conducted for each target type in analyses regressing arousal and disgust on perceived certainty, random intercepts were removed, and analyses were modeled as linear regressions. Because several variables were skewed, we interpreted p-values with caution to decrease the risk of type-I errors. Although we conventionally report also two-sided $p$-values $<.05$ as statistically significant, we interpret only two-sided $p$-values $<.01$ as a convincing rejection of the null hypothesis.

\subsection{Open Data}


Scripts for all analyses and anonymized data are available at the Open Science Framework (link to personal site omitted during review).

\section{Results}

\subsection{Descriptive Results}

The data included 7,640 observations. Of these, 4,849 observations were from older respondents for younger generation targets (i.e., biological children, stepchildren, nieces/nephews, and/or child of a friend) and 2,791 observations were from younger respondents for older generation targets (i.e., biological parents, stepparents, aunts/uncles, and/or parents of a friend). The observations per respondent ranged from 1 to 5. First, we investigated the mean levels of selfreported sexual arousal and disgust. The mean for sexual arousal was $4.74(S D=15.93)$ and the mean for disgust $95.02(S D=15.73)$. The correlation between sexual arousal and disgust was, as expected, strongly negative, $r=-0.76, p<.001$. See Table 1 for descriptive information by category of target individual.

Table 1

Descriptive Information by Category of Target Type

\begin{tabular}{|c|c|c|c|c|c|c|c|c|c|c|}
\hline \multirow[t]{2}{*}{ Target Type } & \multirow{2}{*}{$\begin{array}{c}\text { Observations } \\
N \\
\end{array}$} & \multicolumn{2}{|c|}{ Target Age } & \multicolumn{2}{|c|}{ Age Difference } & \multicolumn{2}{|c|}{ Arousal } & \multicolumn{2}{|c|}{ Disgust } & \multirow[b]{2}{*}{$r$} \\
\hline & & $M$ & $S D$ & $M$ & $S D$ & $M$ & $S D$ & $M$ & $S D$ & \\
\hline Older Generation & 4849 & 57.75 & 12.00 & 27.65 & 10.27 & 5.32 & 16.88 & 94.72 & 16.72 & -.79 \\
\hline Biological Parent & 1379 & 59.99 & 9.08 & 29.78 & 5.78 & 2.48 & 11.11 & 97.62 & 10.44 & -.65 \\
\hline Maternal Aunt/Uncle & 989 & 56.17 & 11.15 & 25.95 & 9.06 & 4.49 & 15.46 & 95.73 & 15.15 & -.83 \\
\hline Paternal Aunt/Uncle & 949 & 57.16 & 11.38 & 27.37 & 9.87 & 5.49 & 17.84 & 95.15 & 16.57 & -.73 \\
\hline Stepparent & 120 & 54.45 & 10.52 & 26.07 & 9.86 & 3.93 & 15.10 & 96.67 & 12.96 & -.77 \\
\hline Friend's Parent ${ }^{\mathrm{a}}$ & 1412 & 57.34 & 14.92 & 27.07 & 13.84 & 8.67 & 20.94 & 90.72 & 21.66 & -.83 \\
\hline Younger Generation & 2791 & 11.83 & 8.11 & -27.38 & 6.58 & 3.74 & 14.06 & 95.56 & 13.84 & -.67 \\
\hline Biological Child & 1040 & 10.99 & 7.25 & -27.99 & 4.97 & 2.74 & 12.58 & 96.40 & 11.95 & -.47 \\
\hline Sister's Child & 331 & 13.27 & 8.97 & -26.80 & 7.37 & 2.90 & 12.62 & 96.13 & 13.56 & -.72 \\
\hline Brother's Child & 366 & 14.67 & 10.22 & -25.13 & 9.96 & 3.26 & 12.74 & 95.40 & 13.52 & -.58 \\
\hline Stepchild & 76 & 16.38 & 7.03 & -24.63 & 6.08 & 2.24 & 11.51 & 98.02 & 8.08 & -.98 \\
\hline Friend's Child $^{\mathrm{a}}$ & 978 & 10.82 & 7.41 & -27.98 & 5.82 & 5.37 & 16.34 & 94.33 & 16.02 & -.79 \\
\hline
\end{tabular}

Note. For arousal and disgust, rated from 0 to 100 , higher values indicate more arousal and more disgust. ${ }^{\mathrm{a}}$ Outliers for age were winsorized to 95 for friend's parent and 48 for friend's child. Values for Age Difference are negative of targets are younger than respondents, and positive if targets are older than respondents. 


\subsection{Sex and Relationship Type}

We then investigated whether incest aversion differed between the two sexes and between different degrees of relatedness. In these analyses, we separated data according to the two data sources. In both subsets of data, we conducted two analyses: first with arousal as the dependent variable, and then with disgust as the dependent variable. In all cases, we used a linear multi-level model with respondent's sex and target type as the fixed predictors and with respondent as a random intercept. In all models, respondent sex, target type, and their interaction significantly predicted the outcome variable (See Table 2 and Figure 1 for details).

Table 2

ANOVA-type Table for Factorial Model of Respondent Sex and Target Type on Incest Aversion

\begin{tabular}{|c|c|c|c|c|c|c|c|c|}
\hline \multirow[t]{3}{*}{ Predictor } & \multicolumn{4}{|c|}{ Older Generation Targets } & \multicolumn{4}{|c|}{ Younger Generation Targets } \\
\hline & \multicolumn{2}{|c|}{ Arousal } & \multicolumn{2}{|c|}{ Disgust } & \multicolumn{2}{|c|}{ Arousal } & \multicolumn{2}{|c|}{ Disgust } \\
\hline & $d f$ & $F$ & $d f$ & $F$ & $d f$ & $F$ & $d f$ & $F$ \\
\hline Respondent Sex & 1 & $72.83 * * *$ & 1 & $86.52 * * *$ & 1 & $16.17 * * *$ & 1 & $15.97 * * *$ \\
\hline Target Type & 4 & $106.52 * * *$ & 4 & $124.22 * * *$ & 4 & $18.12 * * *$ & 4 & $13.43 * * *$ \\
\hline Respondent Sex x Target Type & 4 & $66.08 * * *$ & 4 & $65.55 * * *$ & 4 & $6.35 * * *$ & 4 & $7.97 * * *$ \\
\hline
\end{tabular}

Note: $* p<.05, * * p<.01$, and $* * * p<.001$

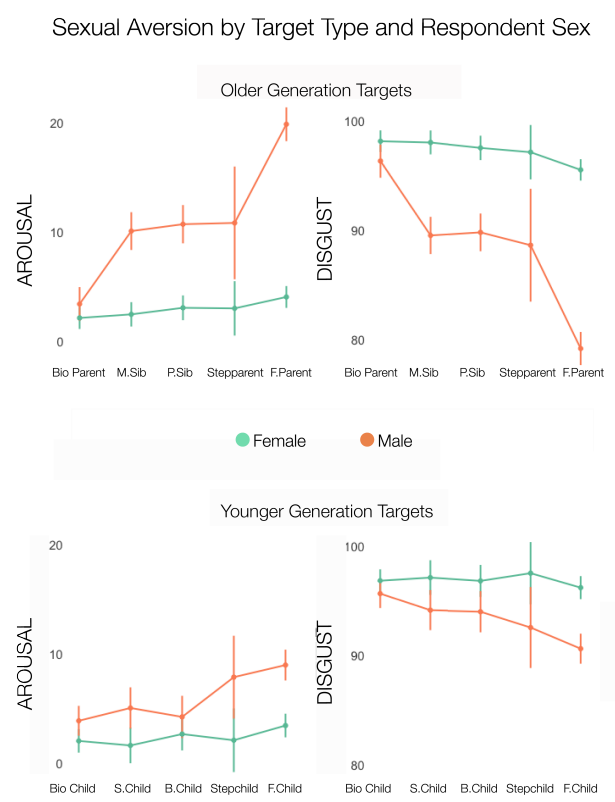

Figure 1. Plots for respondent sex and target type on arousal and disgust for older generation targets (Panels A and B) and younger generation targets $(C$ and $D)$. Higher values indicate higher arousal and disgust. Error bars represent $95 \%$ confidence intervals. M. Sib = Aunt/Uncle via mother, P. Sib = Aunt/Uncle via father, F. Parent = Friend's parent; S. Child = Sister's child; P. Child = Brother's child; and F. Child $=$ Friend's child. 


\section{INTERGENERATIONAL INCEST AVERSION}

As expected, women displayed a stronger sexual aversion than men. Women reported lower levels of arousal and higher levels of disgust independently of whether they responded from the perspective of a younger or an older generation. We also found that target relatedness moderated the association. In general, the more closely related the respondent and target individual, the stronger the aversion. This pattern was clearer for men than women. (See Tables A and B in Appendix for pairwise comparisons for all levels).

\subsection{Relatedness Certainty}

In the following analyses, data were limited to include only relatives. This means that biological parents, mother's siblings (i.e., maternal aunts and uncles) and father's siblings (i.e., paternal aunts and uncles) were included for older generation targets, and biological children, sister's children (i.e., nieces and nephews via a sister) and brother's children (nieces and nephews via a brother) included for younger generation targets. To test whether subjective certainty in relatedness predicted incest aversion, we conducted a series of linear multi-level regression with relatedness certainty as a predictor and arousal and disgust as the outcome variable. Analyses were conducted separately for each target. As expected, all associations between subjective relatedness certainty and arousal were negative (i.e., the more uncertain, the higher the arousal) and all associations between subjective relatedness certainty and disgust were positive (i.e., the more uncertain, the less disgusted). See Table 3 for estimates.

Table 3

Associations between Relatedness Certainty and Incest Aversion for each Biological Relative

\begin{tabular}{|c|c|c|c|c|c|c|}
\hline \multirow[t]{2}{*}{ Target Type } & \multicolumn{3}{|c|}{ Arousal } & \multicolumn{3}{|c|}{ Disgust } \\
\hline & $B$ & $S E$ & $t$ & $B$ & $S E$ & $t$ \\
\hline \multicolumn{7}{|l|}{ Older Generation } \\
\hline Biological Parent & -0.32 & 0.02 & $-13.00 * * *$ & 0.34 & 0.02 & $14.95^{* * *}$ \\
\hline Maternal Aunt/Uncle & -0.24 & 0.03 & $-8.20 * * *$ & 0.18 & 0.03 & $6.23 * * *$ \\
\hline Paternal Aunt/Uncle & -0.22 & 0.03 & $-7.10 * * *$ & 0.21 & 0.03 & $7.00 * * *$ \\
\hline \multicolumn{7}{|l|}{ Younger Generation } \\
\hline Biological Child ${ }^{\mathrm{a}}$ & -0.65 & 0.04 & $-14.73 * * *$ & 0.66 & 0.04 & $16.60 * * *$ \\
\hline Sister's Child & -0.31 & 0.04 & $-8.35 * * *$ & 0.37 & 0.04 & $9.32 * * *$ \\
\hline Brother's Child & -0.43 & 0.04 & $-9.74 * * *$ & 0.39 & 0.05 & $7.96^{* * *}$ \\
\hline
\end{tabular}




\subsection{Target Age and Respondent Age}

An exploratory analysis of the association between respondent age and aversion showed that respondent age was positively associated with aversion for male respondents $(B=-0.14, S E$ $=0.06 . t=-2.15, p<.05$ for arousal and $B=0.16, S E=0.06, t=2.40, p<.05$ for disgust). Interestingly, this association was negative for women $(B=0.07, S E=0.29, t=2.61, p<01$ for arousal and $B=-0.06, S E=0.03, t=-2.17, p<.01$ for disgust). In other words, aversion decreased as men got younger and women got older.

We then investigated how target age was related to the strength of incest aversion. We modeled data using a linear multi-level regression with target age and target type (e.g., targets from a younger generation, such as biological children, and nieces/nephews, and targets from an older generation, such as biological parents and aunts/uncles) as categorical predictors. We conducted separate analyses for the two outcome variables (arousal and disgust). Target age was defined as below 15, 15-50, and above 50 years of age. For male respondents of the older generation, we found that target age was positively associated with arousal, $F(1)=10.31, p<.01$, and negatively associated with disgust $F(1)=7.13, p<.01$. Target age also interacted with target type, $F(4)=14.59, p<.01$ and $F(4)=18.66, p<.01$. The estimates showed a statistically significant difference for friend's daughters, with less aversion reported for fertile (vs. young) targets. For male respondents of the younger generation, we also found that target age was associated with arousal and disgust, $F(1)=9.96, p<.01$ and $F(1)=14.44, p<.001$. Again, target age interacted with target type, $F(4)=5.28, p<.001$ and $F(4)=5.00, p<.001$. There was a statistically significant difference for friend's mothers and (at an alpha level of .05) for maternal aunts, so that less aversion was reported for fertile (vs. senescent) targets. (See table 4). 
For female respondents of the older generation, target age was associated with arousal, $F(1)=7.41, p<.01$, but not disgust, $F(1)=0.11, p=.74$. Target age, however, interacted with target type for both arousal and disgust, $F(4)=3.96, p<.01$ and $F(4)=7.6, p<.001$. An examination of the estimates revealed a statistically significant difference in arousal for friend's sons, so that more arousal and less disgust was reported for fertile (vs. young) targets. For female respondents of the younger generation, target age was not directly associated with arousal and disgust, $F(1)=1.71, p=.19$ and $F(1)=0.56, p=.46$. Neither did target age interacted with target type, $F(4)=2.08, p=.08$ and $F(4)=0.65, p<.001$. (See table 5). Because respondent age was related to aversion, we also ran the above analysis with respondent age as a covariate. There were no noteworthy differences between the two sets of analyses. (Analyses controlling for respondent age are available at the project's Open Science Framework site). 


\section{INTERGENERATIONAL INCEST AVERSION}

Table 4

Sexual Arousal and Disgust for each Age Category and Target Type for Male Respondents

\begin{tabular}{|c|c|c|c|c|c|c|c|c|c|c|c|c|}
\hline \multirow{3}{*}{$\begin{array}{l}\text { Target Type } \\
\text { Older Generation }\end{array}$} & \multicolumn{6}{|c|}{ Arousal } & \multicolumn{6}{|c|}{ Disgust } \\
\hline & \multicolumn{2}{|c|}{ Fertile } & \multicolumn{2}{|c|}{ Senescent } & \multicolumn{2}{|c|}{ Contrast } & \multicolumn{2}{|c|}{ Fertile } & \multicolumn{2}{|c|}{ Senescent } & \multicolumn{2}{|c|}{ Contrast } \\
\hline & $M$ & $S E$ & $\bar{M}$ & $\bar{S} E$ & $t$ & $d f$ & $M$ & $S E$ & $\bar{M}$ & SE & $t$ & $d f$ \\
\hline Biological mother & 5.51 & 2.28 & 2.84 & 1.15 & 1.10 & 1262.01 & 94.19 & 2.34 & 96.79 & 1.18 & -1.04 & 1268.03 \\
\hline Maternal aunt & 14.41 & 2.25 & 8.30 & 1.36 & $2.44 *$ & 1182.38 & 85.50 & 2.31 & 91.02 & 1.40 & $-2.14 *$ & 1189.57 \\
\hline Paternal aunt & 11.84 & 2.49 & 10.12 & 1.36 & 0.63 & 1205.04 & 88.39 & 2.56 & 90.00 & 1.40 & -0.58 & 1211.95 \\
\hline Stepmother & 16.49 & 5.78 & 10.37 & 5.28 & 0.79 & 1262.01 & 79.55 & 5.96 & 94.32 & 5.45 & -1.84 & 1171.94 \\
\hline \multirow[t]{2}{*}{ Friend's mother } & 15.98 & 1.23 & 30.27 & 1.85 & $6.88 * * *$ & 1232.50 & 69.12 & 1.90 & 82.95 & 1.26 & $-6.46^{* * *}$ & 1238.92 \\
\hline & \multicolumn{2}{|c|}{ Young } & \multicolumn{2}{|c|}{ Fertile } & \multicolumn{2}{|c|}{ Contrast } & \multicolumn{2}{|c|}{ Young } & \multicolumn{2}{|c|}{ Fertile } & \multicolumn{2}{|c|}{ Contrast } \\
\hline Younger Generation & $\bar{M}$ & $S E$ & $M$ & $S E$ & $t$ & $d f$ & $\bar{M}$ & $S E$ & $M$ & $S E$ & $t$ & $d f$ \\
\hline Biological daughter & 3.89 & 0.95 & 3.80 & 1.31 & -0.06 & 973.91 & 95.09 & 0.93 & 96.69 & 1.26 & 1.07 & 913.02 \\
\hline Sister's daughter & 4.42 & 1.50 & 5.75 & 1.71 & 0.58 & 797.54 & 94.68 & 1.42 & 93.61 & 1.61 & -0.53 & 783.57 \\
\hline Brother's daughter & 3.52 & 1.60 & 5.62 & 1.66 & 0.96 & 791.50 & 94.35 & 1.52 & 93.14 & 1.57 & -0.60 & 778.37 \\
\hline Stepdaughter & 4.07 & 4.20 & 9.24 & 2.94 & 1.02 & 752.68 & 95.07 & 3.90 & 91.67 & 2.73 & -0.72 & 744.88 \\
\hline Friend's daughter & 4.32 & 1.01 & 17.39 & 1.29 & $8.75 * * *$ & 797.54 & 95.09 & 0.99 & 82.57 & 1.24 & $-8.95 * * *$ & 891.78 \\
\hline
\end{tabular}

Note. For arousal and disgust, rated from 0 to 100 , higher values indicate more arousal and more disgust. $* p<.05, * * p<.01$, and $* * * p<.001$ 
Table 5

Sexual Arousal and Disgust for each Age Category and Target Type for Female Respondents

\begin{tabular}{|c|c|c|c|c|c|c|c|c|c|c|c|c|}
\hline \multirow{3}{*}{$\begin{array}{c}\text { Target Type } \\
\text { Older Generation }\end{array}$} & \multicolumn{6}{|c|}{ Arousal } & \multicolumn{6}{|c|}{ Disgust } \\
\hline & \multicolumn{2}{|c|}{ Fertile } & \multicolumn{2}{|c|}{ Senescent } & \multicolumn{2}{|c|}{ Contrast } & \multicolumn{2}{|c|}{ Fertile } & \multicolumn{2}{|c|}{ Senescent } & \multicolumn{2}{|c|}{ Contrast } \\
\hline & $M$ & $S E$ & $M$ & $S E$ & $t$ & $d f$ & $M$ & $S E$ & $M$ & $S E$ & $t$ & $d f$ \\
\hline Biological father & 2.25 & 0.77 & 2.07 & 0.42 & 0.24 & 2724.42 & 98.01 & 0.73 & 98.02 & 0.39 & -0.26 & 2745.62 \\
\hline Maternal uncle & 2.97 & 0.63 & 2.17 & 0.49 & 1.18 & 2705.77 & 97.99 & 0.59 & 98.13 & 0.46 & -0.22 & 2638.02 \\
\hline Paternal uncle & 2.82 & 0.68 & 3.17 & 0.49 & -0.49 & 2621.63 & 97.13 & 0.64 & 97.77 & 0.46 & -0.93 & 2649.50 \\
\hline Stepfather & 3.49 & 1.48 & 3.08 & 1.06 & 0.23 & 2632.61 & 97.26 & 1.41 & 96.76 & 1.01 & 0.29 & 2581.45 \\
\hline \multirow[t]{2}{*}{ Friend's father } & 5.82 & 0.69 & 3.58 & 0.42 & $3.21 * *$ & 2705.77 & 94.65 & 0.66 & 95.97 & 0.40 & 1.96 & 2725.95 \\
\hline & \multicolumn{2}{|c|}{ Young } & \multicolumn{2}{|c|}{ Fertile } & \multicolumn{2}{|c|}{ Contrast } & \multicolumn{2}{|c|}{ Young } & \multicolumn{2}{|c|}{ Fertile } & \multicolumn{2}{|c|}{ Contrast } \\
\hline Younger Generation & $M$ & $S E$ & $M$ & $S E$ & $t$ & $d f$ & $M$ & $S E$ & $M$ & $S E$ & $t$ & $d f$ \\
\hline Biological son & 1.76 & 0.52 & 2.49 & 0.62 & 1.09 & 1391.30 & 96.41 & 0.50 & 97.60 & 0.61 & 1.71 & 1462.63 \\
\hline Sister's son & 1.62 & 0.82 & 1.96 & 0.88 & 0.31 & 1155.38 & 95.87 & 0.85 & 98.50 & 0.89 & $2.27 *$ & 1180.82 \\
\hline Brother's son & 1.69 & 0.76 & 3.84 & 0.79 & $2.20 *$ & 1164.74 & 97.25 & 0.78 & 96.61 & 0.81 & -0.62 & 1191.75 \\
\hline Stepson & 1.43 & 1.90 & 3.01 & 1.29 & 0.71 & 1118.40 & 96.86 & 2.02 & 97.69 & 1.37 & 0.34 & 1135.06 \\
\hline Friend's son & 2.21 & 0.51 & 5.85 & 0.64 & $5.30 * * *$ & 1357.44 & 97.20 & 0.50 & 94.30 & 0.65 & $-4.02 * * *$ & 1423.53 \\
\hline
\end{tabular}




\section{INTERGENERATIONAL INCEST AVERSION}

\section{Co-residence Duration and Incest Aversion}

Finally, we conducted an exploratory test of whether the proportion of co-residence duration predicted incest aversion in parents of biological and step-children. Proportion of coresidence duration was measured in years from the child's birth to 18 years of age (or until the child's current age). Because children varied in age, with some children being quite young, we included target age as a co-variate. We did not find that co-residence predicted sexual arousal or disgust for biological fathers or biological mothers, nor for step-fathers or step-mothers. (See

\section{Table 6.)}

Table 6

Proportion of Co-Residence Duration with Target Child and Incest Aversion in Adults

\begin{tabular}{|c|c|c|c|c|c|c|c|c|c|c|c|}
\hline & \multicolumn{3}{|c|}{ Co-residence Duration } & \multicolumn{4}{|c|}{ Sexual Arousal } & \multicolumn{4}{|c|}{ Disgust } \\
\hline & $M$ & $S D$ & $n$ & $B$ & $S E$ & $t$ & $p$ & $B$ & $S E$ & $t$ & $p$ \\
\hline Biological Mothers & .97 & .11 & 596 & -5.42 & 3.96 & -1.37 & .17 & -2.36 & 3.85 & -0.61 & .54 \\
\hline Biological Fathers & .92 & .20 & 390 & 0.22 & 3.98 & 0.06 & .96 & 0.09 & 3.71 & 0.03 & .98 \\
\hline Step Mothers & .20 & .23 & 48 & -1.33 & 2.51 & -0.53 & .60 & 1.05 & 1.94 & 0.54 & .59 \\
\hline Step Fathers & .35 & .28 & 28 & 23.81 & 12.87 & 1.85 & .08 & -17.42 & 8.84 & -1.97 & .06 \\
\hline
\end{tabular}

Note: Co-residence is measured as the proportion of the child's life (in years) until 18 years of age that the respondent and the child has been living together. Higher co-residence values describe longer co-residence duration. Regression analyses controls for respondent age and object age.

\section{Discussion}

We investigated intergenerational incest aversion between biological family members and socio-legal family members. We additionally included unrelated individuals from outside the family. Our study is the first study to investigate intergenerational incest aversion in such a comprehensive manner. We hypothesized that $i$ ) women would display a stronger incest aversion than men, ii) that stronger incest aversion would be displayed to closely (vs. more distant) biologically related individuals, $\mathrm{iii}$ ) the subjective certainty in biological relatedness would be positively associated with incest aversion, and $i v$ ) the age of unrelated (but not the age of related) individuals would be associated with sexual aversion. 


\section{INTERGENERATIONAL INCEST AVERSION}

As expected, women reported higher incest aversion than men. For men, but not women, we found that an aversion towards more distant (vs. closer) relatives was weaker. The strength of incest aversion towards biological relatives was, as expected, positively associated with increased subjective certainty in relatedness. Analyses also showed that for friend's children and friend's parents, less sexual aversion was reported to fertile (vs. young or senescent) individuals. Moreover, we found that disgust and sexual arousal were strongly, and negatively correlated across all different target types, providing further evidence of disgust down-regulating sexual arousal towards relatives.

\subsection{Sex and Relationship Type}

The findings regarding sex and relationship type are consistent with prior research. As in previous studies (e.g., Fessler \& Navarrete, 2004; Marcinkowska et al., 2013), we found that the thought of incest evoked more disgust and less arousal in women than it did in men. Women's higher incest aversion is thought to reflect that the consequences of incest are considerably higher for women than men (Trivers, 1972). Furthermore, due the nature of childbirth, women, but not men, can be certain of their biological relatedness to a child, and this can also be a factor that increases incest aversion towards their own children.

Similar to previous research (Antfolk, Lieberman, et al., 2012; Lespiau \& Kaminski, 2016), we also found some indications that the strength of incest aversion is a function of relatedness. In all cases, imagining sex with unrelated individuals from outside the family elicited less sexual aversion. With respect to imagining sex with an individual from an older generation, we found a clear pattern, where aversion increased with degree of relatedness. This pattern was more obvious in men than in women. These findings are in line with theory that suggests that human incest aversion is sensitive to the reproductive costs of inbreeding, which, in turn depend 


\section{INTERGENERATIONAL INCEST AVERSION}

on the degree of relatedness (Haig, 1999; Lieberman \& Antfolk, 2015). With respect to imagining sex with someone of a younger generation, the corresponding patterns were less clear. Generally, point estimates followed the predicted order, but the magnitude of the differences were smaller in this case, compared to when respondents imagined sex with someone of the older generation. This could be because many of the younger generation targets were not adults, decreasing the amount of sexual interest in both related and unrelated individuals. In support of this explanation, the patterns were clearer for fertile (vs. young) targets.

A particularly interesting comparison is that between step-children and biological children. Victimization studies suggest that the likelihood of sexual abuse in step-relationships between a father and a daughter is markedly higher compared to when a child is biologically related to its parent (Sariola \& Uutela, 1996). Although fathers reported a weaker incest aversion towards step-children than towards biological children, this difference was not statistically significant. Additionally, daughters reported similar levels of incest aversion to biological fathers and step-fathers. This may reflect the influence of incest taboos, where conscious awareness of being unrelated does not allay aversion to the notion of sex within the family unit. It is unclear whether the proximate mechanisms regulating incest aversion are closed or open to influences from other mechanisms. For example, it is possible that actively thinking about a step-child as part of the family activates the same type of aversion that biological fathers experience to their biological daughters. Another interesting possibility is that sexual interest in a step-child could decrease sexual access to the child's parent, with whom the respondents are in a relationship, if it was ever discovered or expressed. This could in turn lead to active suppression of sexual interest in a step-child. Both of these explanations remain untested. Interestingly, co-residence duration was not associated with incest aversion in parents to biological or step-children. Because statisti- 


\section{INTERGENERATIONAL INCEST AVERSION}

cal power was low and Type II errors are possible, and it is difficult to draw any conclusions regarding a possible effect of co-residence in parent-child dyads.

\subsection{Relatedness Certainty}

As suggested in previous research (Antfolk et al., 2014; Lieberman et al., 2007; Tal \& Lieberman, 2007), relatedness certainty can play an important role in understanding incest aversion. If an individual is unsure about their genetic relationship to a purported relative, we expect incest aversion is to be decreased. In turn, the likelihood to commit incest might be increased. In the current study, we measured self-reported arousal and disgust, and not actual behavior. The finding that decreased relatedness certainty is associated with decreased incest aversion is, nevertheless, of value also to understanding risk factors of intra-familial sexual abuse and could be useful in forensic investigations of alleged abuse. Future studies should investigate the role of perceived relatedness as a risk factor for incestuous abuse.

\subsection{Age and Incest Aversion}

The age of friend's children and friend's parents, that is, the age of unrelated individuals from outside the family, was associated with sexual aversion in a predictable way, with less sexual aversion being reported for fertile (vs. young or senescent) individuals. This is in line with previous research on sexual age preferences (e.g., Antfolk, 2017; Kenrick \& Keefe, 1992), reflecting an increased interest in individuals of high reproductive value. We found no convincing evidence that the age of a biological relative was associated with sexual arousal and disgust. This could explain the finding that, in cases of sexual abuse, increased age increases risk of victimization in extra-familial sexual abuse but not for intra-familial sexual abuse (Seto, Babchishin, Pullman, \& McPhail, 2015; Ventus, Antfolk, \& Salo, 2017). Female sexual aversion to fertile (vs. young) nephews, and male sexual aversion to fertile (vs. senescent) maternal aunts was lower 


\section{INTERGENERATIONAL INCEST AVERSION}

(although not statistically significant at our adjusted alpha level of .01). It is possible that incest aversion is not substantially decreased for close relatives of high reproductive value. It is also possible that the absence of an association between target age and aversion in the case of close relatives is due to floor and ceiling effects, respectively.

\subsection{Limitations and Future Directions}

The current study has several limitations. Respondents were asked to self-report sexual arousal and disgust to prompts asking them to imagine sex with people they actually knew. The first limitation is that respondent's willingness to imagine the scenarios might have been limited. After all, we sometimes asked them to imagine taboo situations that, in many cases, also describe an illegal activity. Although the anonymity of our survey design was aimed to decrease the effects of socially desirable responding, it is still possible that sexual arousal was under-reported, and disgust was over-reported.

A related limitation concerns ceiling and floor effects. For example, women reported stronger overall disgust to incest, which might obscure differences (e.g., sex with son versus sex with nephew) that could not be captured by our response scale. An examination of female responses suggest that data was skewed and that the point estimates were very close to ceiling (approximately 1-4 points below the highest value, with more variation below the point estimate than above it). Therefore, it is difficult to distinguish between the absence of a difference and failing to detect a "true" difference. Moreover, the skewed, non-normal distribution of responses renders effect sizes difficult to interpret. Because of this limitation, future research could employ physiological measures, such as electromyography (e.g., De Smet et al., 2014). Physiological measures could also circumvent social desirability in responding. Another option is the use of magnitude estimation scaling rather than absolute rating, a method that has been successfully 


\section{INTERGENERATIONAL INCEST AVERSION}

used to examine perceived wrongness of crimes against people varying in biological kinship (Quinsey, Lalumière, Querée, \& McNaughton, 1999).

With these limitations in mind, the current study also has several strengths. Most previous experimental studies have not sufficiently distinguished between different biological and socio-legal family members, and currently the differences between these two types of intrafamilial abuse are not fully understood (Pullman, Sawatsky, Babchishin, McPhail, \& Seto, 2017). The current study provides novel information of relevance to research on intra-familial child sexual abuse. By including several different relationship types, our study contributes a unique and extensive overview of differences in potential risk factors between various forms of intrafamilial abuse.

\subsection{Conclusion}

The current study advances the understanding of incest aversion to include a range of understudied forms of intergenerational relationships. In line with previous studies on incest aversion towards siblings and cousins, we found that women report stronger incest aversion than men in intergenerational contexts as well. Additionally, we found that the degree of relatedness modulates the strength of incest aversion: incest aversion tends to be stronger between closer relatives. The exception to this pattern is seen in step-relationships, for which incest aversion is higher than expected from existing theory, regardless of co-residence duration. Subjective relatedness certainty also modulates the strength of incest aversion. A decreased certainty in relatedness is associated with a decrease in incest aversion. Unlike for unrelated individuals, age does not seem to modulate sexual interest in related individuals. We suggest that the findings of the current study be considered in ongoing research on incestuous abuse. 


\section{INTERGENERATIONAL INCEST AVERSION}

\section{References}

Albrecht, A., Antfolk, J., Lieberman, D., Harju, C., Sandnabba, K., \& Santtila, P. (2014). The Finn-Kin study: A sample and method description of a Finnish population-based study of kin-recognition, incest aversion and altruism. Journal of Social Sciences Research, 6(1), 915-926.

Anderson, K. G., Kaplan, H., \& Lancaster, J. B. (2007). Confidence of paternity, divorce, and investment in children by Albuquerque men. Evolution and Human Behavior, 28(1), 1-10. http://doi.org/10.1016/j.evolhumbehav.2006.06.004

Antfolk, J. (2017). Age limits: Men's and women's youngest and oldest considered and actual sex partners. Evolutionary Psychology, 1-9. http://doi.org/doi/10.1177/1474704917690401

Antfolk, J., Karlsson, L. C., Söderlund, J., \& Szala, A. (2017). Willingness to invest in children: Psychological kinship estimates and emotional closeness. Evolutionary Psychology, 15(2). http://doi.org/10.1177/1474704917705730

Antfolk, J., Karlsson, M., Bäckström, A., \& Santtila, P. (2012). Disgust elicited by third-party incest: The roles of biological relatedness, co-residence, and family relationship. Evolution and Human Behavior, 33(3), $217-223$. http://doi.org/10.1016/j.evolhumbehav.2011.09.005

Antfolk, J., Lieberman, D., Albrecht, A., \& Santtila, P. (2014). The self-regulation effect of fertility status on inbreeding aversion: When fertile, disgust increases more in response to descriptions of one's own than of others' inbreeding. Evolutionary Psychology, 12(3), 621-631.

Antfolk, J., Lieberman, D., \& Santtila, P. (2012). Fitness costs predict inbreeding aversion irrespective of selfinvolvement: Support for hypotheses derived from evolutionary theory. PLoS ONE, 7(11). http://doi.org/10.1371/journal.pone.0050613

Antfolk, J., Lindqvist, H., Albrecht, A., \& Santtila, P. (2014). Self-reported availability of kinship cues during childhood is associated with kin-directed behavior to parents in adulthood. Evolutionary Psychology, 12(1), $148-166$.

Antfolk, J., Salo, B., Alanko, K., Bergen, E., Corander, J., Sandnabba, N. K., \& Santtila, P. (2015). Women's and men's sexual preferences and activities with respect to the partner's age: Evidence for female choice. Evolution and Human Behavior, 36(1), 73-79. http://doi.org/10.1016/j.evolhumbehav.2014.09.003

Apicella, C. L., \& Marlowe, F. W. (2004). Perceived mate fidelity and paternal resemblance predict men's investment in children. Evolution and Human Behavior. http://doi.org/10.1016/j.evolhumbehav.2004.06.003

Bancroft, J., \& Janssen, E. (2000). The dual control model of male sexual response: A theoretical approach to centrally mediated erectile dysfunction. Neuroscience and Biobehavioral Reviews, 24, 571-579. http://doi.org/10.1016/S0149-7634(00)00024-5

Bates, D., Maechler, M., Bolker, B. M., \& Walker, S. (2015). Fitting Linear Mixed-Effects Models Using lme4. Journal of Statistical Software, 67(1), 1-48. http://doi.org/10.18637/jss.v067.i01

Bergen, E., Antfolk, J., Jern, P., Alanko, K., \& Santtila, P. (2013). Adults' sexual interest in children and adolescents online: A quasi-experimental study. International Journal of Cyber Criminology, 7(2), 94-111.

Bevc, I., \& Silverman, I. (1993). Early proximity and intimacy between siblings and incestuous behavior: A test of 


\section{INTERGENERATIONAL INCEST AVERSION}

the Westermarck theory. Ethology and Sociobiology, 14(3), 171-181. http://doi.org/10.1016/01623095(93)90004-2

Billingsley, J., Antfolk, J., Santtila, P., \& Lieberman, D. (2018). Cues to paternity: Do partner fidelity and offspring resemblance predict daughter-directed sexual aversions? Evolution and Human Behavior. http://doi.org/https://doi.org/10.1016/j.evolhumbehav.2018.02.001

Bittles, A. H., \& Neel, J. V. (1994). The costs of human inbreeding and their implications for variations at the DNA level. Nature Genetics, 8(2), 117-121. http://doi.org/10.1038/ng1094-117

Bjorklund, D. F., \& Kipp, K. (1996). Parental investment theory and gender differences in the evolution of inhibition mechanisms. Psychological Bulletin, 120(2), 163-188.

Bressan, P., \& Kramer, P. (2015). Human kin detection. Wiley Interdisciplinary Reviews: Cognitive Science. http://doi.org/10.1002/wcs.1347

Bretman, A., Wedell, N., \& Tregenza, T. (2004). Molecular evidence of post-copulatory inbreeding avoidance in the field cricket Gryllus bimaculatus. Proceedings of the Royal Society B: Biological Sciences, 271(1535), 159164. http://doi.org/10.1098/rspb.2003.2563

Charlesworth, D., Charlesworth, D., Willis, J. H., \& Willis, J. H. (2009). The genetics of inbreeding depression. Nature Reviews. Genetics, 10(11), 783-96. http://doi.org/10.1038/nrg2664

Darwin, C. (1876). The effects of cross and self fertilisation in the vegetable kingdom. John Murray. http://doi.org/10.1017/CBO9781107415324.004

De Jong, P. J., Van Overveld, M., \& Borg, C. (2013). Giving in to arousal or staying stuck in disgust? Disgust-based mechanisms in sex and sexual dysfunction. Journal of Sex Research. http://doi.org/10.1080/00224499.2012.746280

De Smet, D., Van Spreybroeck, L., \& Verplaetse, J. (2014). The Westermarck effect revisited: A psychophysiological study of sibling incest aversion in young female adults. Evolution and Human Behavior, 35(1), 34-42.

Fessler, D. M. T., \& Navarrete, C. D. (2004). Third-party attitudes toward sibling incest Evidence for Westermarck's hypotheses. Evolution and Human Behavior, 25(5), 277-294. http://doi.org/10.1016/j.evolhumbehav.2004.05.004

Frankham, R. (1995). Inbreeding and Extinction : A Threshold Effect. Conservation Biology, 9(4), 792-799. http://doi.org/10.1046/j.1523-1739.1995.09040792.x

Haig, D. (1999). Assymetric Relations: Internal Conflicts and the Horror of Incest. Evolution and Human Behavior, 20,83-98.

Hayes, A. F. (1995). Age preferences for same- and opposite-sex partners. Journal of Social Psychology, 135(2), 125-133. http://doi.org/10.1080/00224545.1995.9711415

Kenrick, D., \& Keefe, R. (1992). Age Preferences in Mates reflect sex differences in mating strategies. Behavioral \& Brain Sciences, 15, 75-91.

Kenrick, D. T., \& Keefe, R. C. (1992). Age preferences in mates reflect sex differences in human reproductive strategies. Behavioral and Brain Sciences, 15(1), 75-91. http://doi.org/10.1017/S0140525X00067595 


\section{INTERGENERATIONAL INCEST AVERSION}

Koukounas, E., \& McCabe, M. P. (2001). Sexual and emotional variables influencing sexual response to erotica: A psychophysiological investigation. Archives of Sexual Behavior, 30(4), 393-408. http://doi.org/10.1023/A:1010261315767

Kurpisz, J., Mak, M., Lew-Starowicz, M., Nowosielski, K., \& Samochowiec, J. (2015). The Dual Control Model of sexual response by J. Bancroft and E. Janssen. Theoretical basis, research and practical issues. Postepy Psychiatrii I Neurologii. http://doi.org/10.1016/j.pin.2015.08.001

Lenth, R. V. (2016). Least-Squares Means: The R-package lsmeans. Journal of Statistical Software, 69(1), 1-33.

Lespiau, F., \& Kaminski, G. (2016). Fitness costs predict emotional, moral, and attitudinal inbreeding aversion. Frontiers in Psychology, 7(NOV). http://doi.org/10.3389/fpsyg.2016.01860

Lieberman, D., \& Antfolk, J. (2015). Human Sexuality and Inbreeding Avoidance.

Lieberman, D., \& Lobel, T. (2011). Kinship on the Kibbutz: coresidence duration predicts altruism, personal sexual aversions and moral attitudes among communally reared peers. Evolution and Human Behavior. http://doi.org/10.1016/j.evolhumbehav.2011.05.002

Lieberman, D., Pillsworth, E. G., \& Haselton, M. G. (2011). Kin affiliation across the ovulatory cycle: Females avoid fathers when fertile. Psychological Science, 22, 13-18.

Lieberman, D., Tooby, J., \& Cosmides, L. (2003). Does morality have a biological basis? An empirical test of the factors governing moral sentiments relating to incest. Proceedings of the Royal Society B: Biological Sciences, 270(1517), 819-826. http://doi.org/10.1098/rspb.2002.2290

Lieberman, D., Tooby, J., \& Cosmides, L. (2007). The architecture of human kin detection. Nature, 445, 727-731. http://doi.org/10.1038/nature05510

Marcinkowska, U. M., Moore, F. R., \& Rantala, M. J. (2013). An experimental test of the Westermarck effect: Sex differences in inbreeding avoidance. Behavioral Ecology, 24(4), 842-845. http://doi.org/10.1093/beheco/art028

Mcdowell, M. A., Brody, D. J., \& Hughes, J. P. (2007). Has Age at Menarche Changed? Results from the National Health and Nutrition Examination Survey (NHANES) 1999 - 2004. Journal of Adolescent Healht, 40, 227231. http://doi.org/10.1016/j.jadohealth.2006.10.002

Parker, H., \& Parker, S. (1986). Father-daugther incest: An emerging perspective. The American Journal of Orthopsychiatry, 51, 531-549.

Pullman, L. E., Sawatsky, M. L., Babchishin, K. M., McPhail, I. V., \& Seto, M. C. (2017). Differences between biological and sociolegal incest offenders: A meta-analysis. Aggression and Violent Behavior. http://doi.org/10.1016/j.avb.2017.01.003

Quinsey, V. L., Lalumière, M. L., Querée, M., \& McNaughton, J. K. (1999). Perceived Crime Severity and Biological Kinship. Human Nature, 10(4), 399-414.

R Development Core Team, R. F. F. S. C. (2008). R: A Language and Environment for Statistical Computing. Vienna Austria R Foundation for Statistical Computing, 1(10), ISBN 3-900051-07-0. http://doi.org/10.1007/978-3-540-74686-7

Rempel, J. K., \& Baumgartner, B. (2003). The relationship between attitudes towards menstruation and sexual 


\section{INTERGENERATIONAL INCEST AVERSION}

attitudes, desires, and behavior in women. Archives of Sexual Behavior, 32(2), 155-63. Retrieved from http://www.ncbi.nlm.nih.gov/pubmed/12710830

Revelle, W. (2016). psych: Procedures for Personality and Psychological Research. R Package, 1-358.

Royzman, E. B., Leeman, R. F., \& Sabini, J. (2008). “you make me sick”: Moral dyspepsia as a reaction to thirdparty sibling incest. Motivation and Emotion, 32(2), 100-108. http://doi.org/10.1007/s11031-008-9089-x

Santtila, P., Antfolk, J., Räfsa, A., Hartwig, M., Sariola, H., Sandnabba, N. K., \& Mokros, A. (2015). Mens sexual interest in children: One-year incidence and correlates in a population-based sample of Finnish male twins. Journal of Child Sexual Abuse, 24(2), 115-134. http://doi.org/10.1080/10538712.2015.997410

Sariola, H., \& Uutela, A. (1996). The prevalence and context of incest abuse in Finland. Child Abuse \& Neglect, 20(9), 843-850.

Schluter, D. P. (2002). Gay Life in the Former USSR: Fraternity without Community. Routledge.

Seto, M. C. (2008). Pedophilia and sexual offending against children. Annual review of sex research (Vol. 15). http://doi.org/10.1037/11639-000

Seto, M. C., Babchishin, K. M., Pullman, L. E., \& McPhail, I. V. (2015). The Puzzle of Intrafamilial Child Sexual Abuse: A Meta-Analysis Comparing Intrafamilial and Extrafamilial Offenders with Child Victims. Clinical Psychology Review, 39, 42-57. http://doi.org/10.1016/j.cpr.2015.04.001

Spielman, D., Brook, B. W., Briscoe, D. A., \& Frankham, R. (2004). Does inbreeding and loss of genetic diversity decrease disease resistance? Conservation Genetics, 5(4), 439-448. http://doi.org/10.1023/B:COGE.0000041030.76598.cd

Stark, R., Schienle, A., Girod, C., Walter, B., Kirsch, P., Blecker, C., ... Vaitl, D. (2005). Erotic and disgustinducing pictures: Differences in the hemodynamic responses of the brain. Biological Psychology, 70(1), 1929. http://doi.org/10.1016/j.biopsycho.2004.11.014

Stevenson, R. J., Case, T. I., \& Oaten, M. J. (2011). Effect of self-reported sexual arousal on responses to sex-related and non-sex-related disgust cues. Archives of Sexual Behavior, 40(1), 79-85. http://doi.org/10.1007/s10508$009-9529-z$

Szulkin, M., Zelazowski, P., Nicholson, G., \& Sheldon, B. C. (2009). Inbreeding avoidance under different null models of random mating in the great tit. Journal of Animal Ecology, 78(4), 778-788. http://doi.org/10.1111/j.1365-2656.2009.01544.x

Tal, I., \& Lieberman, D. (2007). Kin detection and the development of sexual aversion: toward and integration of theories on family sexual abuse. In C. A. Salmon \& T. K. Schackelford (Eds.), Family Relationships - An Evolutionary Perspective (pp. 205-229). New York: Oxford University Press.

Thornhill, N. W. (1991). An evolutionary analysis of rules regulating human inbreeding and marriage. Behavioral and Brain Sciences, 14(2), 247-293. http://doi.org/10.1017/S0140525X00066449

Tidefors, I., Arvidsson, H., Ingevaldson, S., \& Larsson, M. (2010). Sibling incest: A literature review and a clinical study. Journal of Sexual Aggression. http://doi.org/10.1080/13552600903511667

Tooby, J. (1982). Pathogens, polymorphism, and the evolution of sex. Journal of Theoretical Biology, 97(4), 557576. 


\section{INTERGENERATIONAL INCEST AVERSION}

Tripodi, F., Eleuteri, S., Giuliani, M., Rossi, R., Livi, S., Petruccelli, I., \& Simonelli, C. (2015). Unusual online sexual interests in heterosexual Swedish and Italian university students. Sexologies.

Trivers, R. L. (1972). Parental Investment and Sexual Selection Introduction. Sexual Selection and the Descent of Man 1871-1971, 136-207. http://doi.org/10.1002/ajpa.1330400226

Ventus, D., Antfolk, J., \& Salo, B. (2017). The Associations between Abuse Characteristics in Child Sexual Abuse : A Meta- Analysis. Journal of Sexual Aggression, (April). http://doi.org/10.1080/13552600.2017.1318963

Westermarck, E. (1891). The History of Human Marriage. London: Macmillian.

Williams, L. M., \& Finkelhor, D. (1995). Paternal caregiving and incest: Test of a Biosocial Model. The American Journal of Orthopsychiatry, 65(1), 101-113. Retrieved from http://www.ncbi.nlm.nih.gov/pubmed/8561191

Wolf, A. (1968). Adopt a Daughter-in-Law, Marry a Sister: A Chinese Solution to the Problem of the Incest Taboo. American AnthropologistNew Series, 70(5), 864-874. http://doi.org/10.2307/669753

Wolf, A. P. (1966). Childhood Association, Sexual Attraction, and the Incest Taboo: A Chinese Case. American AnthropologistNew Series, 68(4), 883-898. http://doi.org/10.1126/science.1204978

Wolf, A. P., \& Durham, W. H. (2004). Inbreeding, Incest, and the Incest Taboo: The State of Knowledge at the Turn of the Century. Stanford: Stanford University Press. 